DOI: 10.12957/demetra.2016.19491

\title{
Qualidade nutricional e físico-química em cenoura (Daucus carota 1.) in natura e minimamente processada
} Nutritional and physicochemical quality in fresh and fresh cut carrot (Dauscardal.)

Ana Carolina Bizinoto Silva' Luenda Camile dos Santos Schuquel' Cassiano Oliveira da Silva' Grazieli Benedetti Pascoal ${ }^{1}$

${ }^{1}$ Curso de Nutrição, Faculdade de Medicina, Universidade Federal de Uberlândia. UberlandiaMG, Brasil.

Correspondência / Correspondence Grazieli Benedetti Pascoal E-mail:grazi_nutri@yahoo.com.br

\section{Resumo}

Introdução: A cenoura (Daucus carota L.) é uma das hortaliças mais produzidas e consumidas pela população brasileira e vem sendo comercializada tanto in natura quanto minimanente processada. Sua qualidade nutricional após o processamento mínimo pode sofrer alterações na composição centesimal e perfil físico-químico. Objetivo: Determinar e comparar a qualidade nutricional e físico-química em cenoura in natura e minimamente processada. Material e Métodos: As cenouras in natura e minimamente processadas foram adquiridas em Uberlândia (MG) e foram determinados: umidade, proteínas, lipídeos, carboidratos "disponíveis", fibras alimentares (FA), cinzas, valor energético total (VET), fenólicos, vitamina C, carotenoides e outros pigmentos, e alguns parâmetros físico-químicos $(\mathrm{pH}$, acidez titulável, sólidos solúveis e atividade antioxidante). Todos os resultados foram analisados pelo teste $t$ com significância de 5\%. Resultados: Os valores médios de umidade, proteínas, lipídios, carboidratos "disponíveis" (diferença), FA, cinzas, VET (kcal/100g), fenólicos, vitamina C, carotenoides totais, licopeno, betacaroteno, clorofila A, clorofila B, atividade antioxidante, sólidos solúveis, acidez titulável, $\mathrm{pH}$ para a cenoura in natura foram, respectivamente: $90,0 \% ; 0,6 \% ; 0,2 \% ; 5,1 \% ; 3,3 \% ; 0,8 \%$; 24,2 kcal/100g; 32,8mg\%; 21,3mg\%; 2,0mg\%; 0,0mg\%; 2,0mg\%; $0,2 \mathrm{mg} \% ; 0,0 \mathrm{mg} \% ; 38,7 \% ; 12,0 \stackrel{\circ}{\mathrm{Brix}} ; 1,4 \% ; 6,0$. Para a cenoura minimamente processada os valores foram, respectivamente: $89,8 \% ; 0,6 \% ; 0,1 \% ; 5,7 \% ; 3,0 \% ; 0,8 \% ; 26,1 \mathrm{kcal} / 100 \mathrm{~g} ; 39,9 \mathrm{mg} \%$; $18,3 \mathrm{mg} \% ; 1,6 \mathrm{mg} \% ; 0,0 \mathrm{mg} \% ; 1,6 \mathrm{mg} \% ; 0,2 \mathrm{mg} \% ; 0,0 \mathrm{mg} \% ; 24,0 \%$; 12,0-Brix; $1,9 \% ; 5,5$. Conclusão: Ao analisar os dois tratamentos de cenoura, pode-se concluir que a cenoura in natura possui maiores 
teores de nutrientes que a cenoura minimamente processada. Esses achados foram importantes e mostraram que mais estudos precisam ser feitos, a fim de investigar o efeito do processamento mínimo em cenoura.

Palavras-chave: Cenoura. Processamento Mínimo. Qualidade Nutricional. Parâmetros Físico-Químicos.

\section{Abstract}

Introduction: Carrot (Daucus carota L.) is one of the most produced and consumed vegetables by Brazilian population and has been commercialized either fresh or fresh cut. The nutritional quality of carrots after processing may change their chemical composition and physicochemical profile. Objective: To determine and compare the nutritional and physicochemical quality in fresh and fresh cut carrot. Material and Methods: Fresh and fresh cut carrots were acquired in Uberlândia, Minas Gerais state, Brazil, and the following parameters were determined: moisture, proteins, lipids, "available" carbohydrates, dietary fiber (DF), ash, total energetic value (TEV), phenolics, vitamin $\mathrm{C}$, carotenoids and other pigments, some physicochemical parameters $(\mathrm{pH}$, titratable acidity, soluble solid and antioxidant activity). All results were analyzed by $t$ test at $5 \%$ significance. Results: The moisture, protein, lipids, carbohydrates (difference), DF, ash, TEV (kcal/100g), phenolics, vitamin C, total carotenoids, lycopene, betacarotene, chlorophyll A, chlorophyll B, antioxidant activity, soluble solids, titratable acidity and $\mathrm{pH}$ for fresh carrot were, respectively: $90.0 \% ; 0.6 \% ; 0.2 \% ; 5.1 \% ; 3.3 \% ; 0.8 \% ; 24.2$ $\mathrm{kcal} / 100 \mathrm{~g} ; 32.8 \mathrm{mg} \% ; 21.3 \mathrm{mg} \% ; 2.0 \mathrm{mg} \% ; 0.0 \mathrm{mg} \% ; 2.0 \mathrm{mg} \%$; $0.2 \mathrm{mg} \%$; $0.0 \mathrm{mg} \%$; 38.7\%; $12.0{ }^{\circ}$ Brix; $1.4 \% ; 6.0$. For fresh cut carrot the values were, respectively: $89.8 \% ; 0.6 \% ; 0.1 \% ; 5.7 \%$; $3.0 \% ; 0.8 \% ; 26.1 \mathrm{kcal} / 100 \mathrm{~g} ; 39.9 \mathrm{mg} \% ; 18.3 \mathrm{mg} \% ; 1.6 \mathrm{mg} \%$; $0.0 \mathrm{mg} \% ; 1.6 \mathrm{mg} \% ; 0.2 \mathrm{mg} \% ; 0.0 \mathrm{mg} \% ; 24.0 \% ; 12.0$ oBrix; $1.9 \%$; 5.5. Conclusion: Analyzing both treatments, on can conclude that fresh carrots have higher nutrient content than fresh cut carrots. These findings were important and showed that further studies must be made, in order to investigate the effect of minimal processing on carrots.

Key words: Carrot. Minimal Processing. Nutritional Quality. Physicochemical Parameters. 


\section{Introdução}

O setor de frutas e hortaliças vem contribuindo para a geração de riquezas do Brasil, por sua produção elevada e diversificada. ${ }^{1}$ Uma tendência atual dos consumidores é a aquisição de produtos que se adequem ao ritmo de vida atual e que sejam, ao mesmo tempo, saudáveis, práticos, convenientes, inovadores e seguros. ${ }^{2}$ Dentro desta perspectiva contemporânea, juntamente com o anseio dos consumidores, surgiram os vegetais minimamente processados (VMPs). ${ }^{3}$ Sucintamente, VMPs são frutas e hortaliças que passam por inúmeros processamentos prévios (etapas de prépreparo), como seleção, limpeza, lavagem, classificação, sanitização, centrifugação, descascamento, corte, embalagem e estocagem, sem que o aspecto fresco do vegetal seja demasiadamente prejudicado., ${ }^{4,5}$

O processamento mínimo de frutas e hortaliças se desenvolveu no Brasil de forma mais consistente a partir dos anos 1990, o que configura atividade recente em comparação aos países desenvolvidos. ${ }^{5}$ Contudo, o mercado de VMPs vem crescendo acentuadamente e se consolidando no país ao longo dos anos. ${ }^{6}$ Cabe lembrar que os principais consumidores se encontram em classes sociais mais favorecidas, pelo fato de o processamento mínimo agregar valor ao produto, tornando-o mais caro em comparação aos produtos in natura. ${ }^{4}$

Os VMPs geralmente apresentam maior perecibilidade quando comparados aos vegetais intactos (in natura), devido ao aumento da taxa respiratória dos vegetais, da atividade microbiológica, da evaporação de água e da perda mais rápida de textura dos alimentos, que podem conferir alterações sensoriais (cor, aroma, sabor) e nutricionais. ${ }^{1}$

De uma maneira geral, as frutas e hortaliças apresentam quantidades apreciáveis de compostos bioativos, sobretudo compostos fenólicos, glicosinolatos, carotenoides e determinadas vitaminas, com destaque para as vitaminas $\mathrm{C}$ e E. ${ }^{7,8}$ Os vegetais submetidos ao processamento mínimo sofrem injúrias teciduais que podem resultar em perdas nutricionais. ${ }^{9}$ Podem-se elucidar diversos exemplos de modificações físico-químicas após o processamento mínimo, tais como a produção de etileno, perda de água e escurecimento enzimático. ${ }^{10}$

A cenoura (Daucus carota L.) é uma hortaliça pertencente ao grupo das raízes tuberosas da família Apiaceae, sendo considerada um dos vegetais mais cultivados no Brasil. ${ }^{11}$ Do ponto de vista nutricional, a cenoura contém carboidratos "disponíveis"; fibras alimentares; proteínas; lipídios; minerais (cálcio, magnésio, potássio, sódio, fósforo, manganês, ferro, cobre e zinco); vitamina C; e carotenoides, com destaque para o $\beta$-caroteno (pró-vitamina A). ${ }^{12}$ Em adição, a cenoura é um dos VMPs mais comercializados e pode ser encontrada em formatos diversos, tais como: cubos, fios, palito, ralada, fatiada, e minicenoura ("cenourete" - baby carrot americana ou "catetinho" formato esférico). ${ }^{9}$ 
Pesquisas envolvendo os VMPs são importantes para apontar aspectos intrínsecos à sua qualidade, visto que houve aumento da aquisição destes alimentos, particularmente com relação à cenoura. Com base no exposto, a presente pesquisa objetivou analisar e comparar a qualidade nutricional e físico-química em cenoura in natura e minimamente processada.

\section{Material e Métodos}

A cenoura (Daucus carota L.), cultivar Nantes, na forma in natura foi adquirida em um estabelecimento comercial localizado no município de Uberlândia, estado de Minas Gerais, proveniente de cultivo de um único produtor da região. A cenoura minimamente processada foi obtida através da mesma amostra in natura e processada em um estabelecimento de processamento mínimo, localizado ns mesma cidade. A cenoura foi coletada no período compreendido entre novembro de 2013 a setembro de 2014. O fluxograma de produção da cenoura minimamente processada consistiu nas seguintes etapas: seleção, pré-lavagem, descascamento manual, cloração, choque térmico em água a $5^{\circ} \mathrm{C}$, corte em máquina (AJM, multiprocessador industrial), centrifugação, embalamento e estocagem. A cenoura in natura foi considerada como "alimento controle", objetivando a comparação de seus resultados com a cenoura minimamente processada.

As amostras de cenoura minimamente processada foram adquiridas no dia de realização das análises e foram provenientes do mesmo lote da cenoura in natura (antes do processamento). A cenoura minimamente processada apresentava-se ralada e acondicionada em embalagem de plástico com atmosfera passiva. A cenoura in natura foi descascada com descascador manual e ralada com o auxílio de um ralador caseiro no momento da realização das análises.

Uma amostra de cenoura in natura (cerca de 3,5 kg) e minimamente processada (cerca de 3,5 $\mathrm{kg}$ ) foi transportada em caixas isotérmicas higienizadas, contendo gelox e encaminhadas para análise ao Laboratório de Bromatologia e Microbiologia de Alimentos da Faculdade de Medicina da Universidade Federal de Uberlândia. O experimento do presente estudo consistiu em: 1 tomada de ensaio, 1 unidade amostral (cerca de 7 quilos de cenoura = cenoura in natura + minimamente processada), 2 tratamentos (cenoura in natura e minimamente processada), 1 local e 3 análises (em triplicata). ${ }^{13-15}$

As metodologias para a determinação de proteínas, lipídios, carboidratos "disponíveis", cinzas, fenólicos, vitamina C, carotenoides totais (licopeno e betacaroteno) e outros pigmentos (clorofila A e clorofila B) e dos parâmetros físico-químicos ( $\mathrm{pH}$, acidez titulável, sólidos solúveis e atividade antioxidante) foram descritas por Da-Paz et al. ${ }^{13}$ e Pacheco et al., ${ }^{15}$ utilizando metodologias 
consolidadas pela Association of Official Analytical Chemists (AOAC) e pelo Instituto Adolfo Lutz, a saber: o teor de lipídios foi determinado pelo método Goldfish, com éter etílico. ${ }^{16}$ As cinzas foram determinadas pelo peso de material que restou após incineração em mufla a $550^{\circ} \mathrm{C}$ por 6 - 8 horas. ${ }^{17}$

As proteínas seguiram a metodologia de micro-Kjeldhal (960.42):18 e para estimar sua quantidade, o valor do nitrogênio foi multiplicado pelo fator de conversão para proteínas vegetais ( $\mathrm{N}$ x 5,75). ${ }^{19}$ A quantificação de carboidratos "disponíveis" foi feita pelo método fenolsulfúrico e expressa na base úmida $(\mathrm{g} / \mathrm{l} 00 \mathrm{~g}) .{ }^{20}$ Os carboidratos "disponíveis" por diferença foram obtidos pela somatória dos valores de umidade, proteínas, lipídios, cinzas, fibras alimentares e subtraídos de $100 .{ }^{19}$ Os fenólicos foram determinados com a utilização do ácido gálico como padrão (mg de equivalentes de ácido gálico - EAG por $100 \mathrm{~g}$ de cenoura na base úmida ). ${ }^{21} \mathrm{~A}$ determinação de vitamina C foi realizada através do método iodométrico (método 364/IV). ${ }^{17}$ Os carotenoides (licopeno e betacaroteno) e outros pigmentos (clorofila A e clorofila B) foram feitos por espectrofotometria. ${ }^{22}$

A atividade antioxidante foi determinada pelo método DPPH (2,2-difenil-1-picril-hidrazil), com a utilização de extrato etanólico. ${ }^{23}$ Para análise dos sólidos solúveis, foi utilizado o método 932.12 e os resultados expressos em ${ }^{\circ}$ Brix. ${ }^{18}$ Para obtenção da acidez titulável, foram acrescentados $50 \mathrm{ml}$ de água destilada para maceração completa das amostras, e cinco gotas de fenolftaleína foram adicionadas na amostra para posterior titulação com hidróxido de sódio a 0,01M até obtenção de coloração rosa. O resultado foi expresso em \% de ácido cítrico. ${ }^{17} \mathrm{O} \mathrm{pH}$ foi feito a partir do método 017/IV e feita a leitura em potenciômetro. ${ }^{17}$

O teor de umidade foi mensurado através da perda de peso da amostra submetida a aquecimento em estufa a 65ํㅡ durante 48 horas. A fibra alimentar foi determinada pelo método não enzimáticogravimétrico (AOAC 993.21), no qual as amostras foram submetidas a precipitação, filtração, secagem e determinação das proteínas e das cinzas com resíduo. ${ }^{18}$

A energia foi expressa em quilocalorias (kcal) e quilojoules (kJ). O valor energético (em kcal) foi calculado multiplicando-se os valores de carboidratos "disponíveis" (por diferença) por $4 \mathrm{kcal} / \mathrm{g}$; proteínas por $4 \mathrm{kcal} / \mathrm{g}$; e lipídios por $9 \mathrm{kcal} / \mathrm{g}$. O valor energético (em kJ) foi obtido pela seguinte fórmula: $\mathrm{kJ}=\mathrm{kcal}$ x $4,184 .^{24}$

A análise estatística foi realizada pelo software SAEG versão 9.1. Para comparação das médias entre os tratamentos (in natura e minimamente processado), foi utilizado o teste $t$ não pareado, considerando-se um nível de significância de $5 \%$. 


\section{Resultados e Discussão}

A tabela 1 apresenta a comparação da composição centesimal e o valor energético $(\mathrm{kcal} / 100 \mathrm{~g}$ e $\mathrm{kJ} / 100 \mathrm{~g}$ ) entre a cenoura in natura e minimamente processada, na base úmida. O teor de umidade, proteínas, carboidratos “disponíveis” (por diferença), fibras alimentares, cinzas e o VET (kcal/100g e kJ/100g) não apresentaram diferenças $(\mathrm{p}>0,05)$ entre a cenoura in natura e minimamente processada. Os valores de lipídios e carboidratos "disponíveis" (pelo método fenol-sulfúrico) apresentaram diferenças $(\mathrm{p}<0,05)$ entre os tratamentos.

Tabela 1. Composição centesimal (g/100g) e valor energético (kcal/100g e kJ/100g) da cenoura (Daucus carota L.) in natura e minimamente processada, na base úmida. Uberlândia-MG, 2013-2014.

\begin{tabular}{lcc}
\hline \multicolumn{1}{c}{ Composição centesimal } & Cenoura in natura & Cenoura MP \\
\hline Umidade & $90,0 \pm 0,14^{\mathrm{a}}$ & $89,8 \pm 0,73^{\mathrm{a}}$ \\
Proteínas & $0,6 \pm 0,02^{\mathrm{a}}$ & $0,6 \pm 0,03^{\mathrm{a}}$ \\
Lipídios & $0,2 \pm 0,02^{\mathrm{a}}$ & $0,1 \pm 0,00^{\mathrm{b}}$ \\
CHO “disponíveis”' & $5,1 \pm 0,19^{\mathrm{a}}$ & $5,7 \pm 0,98^{\mathrm{a}}$ \\
CHO “disponíveis”2 & $7,7 \pm 0,31^{\mathrm{a}}$ & $6,8 \pm 0,10^{\mathrm{b}}$ \\
FAT & $3,3 \pm 0,14^{\mathrm{a}}$ & $3,0 \pm 0,26^{\mathrm{a}}$ \\
Cinzas & $0,8 \pm 0,00^{\mathrm{a}}$ & $0,8 \pm 0,03^{\mathrm{a}}$ \\
VET (kcal/100g) & $24,2 \pm 0,58^{\mathrm{a}}$ & $26,1 \pm 3,77^{\mathrm{a}}$ \\
VET $(\mathrm{kJ} / 100 \mathrm{~g})$ & $101,4 \pm 2,42^{\mathrm{a}}$ & $109,8 \pm 15,83^{\mathrm{a}}$ \\
\hline
\end{tabular}

Valores médios \pm desvio-padrão; $\mathrm{CHO}^{1}=$ carboidratos "disponíveis" por diferença; $\mathrm{CHO}^{2}=$ carboidratos "disponíveis" pelo método fenol-sulfúrico; FAT = fibra alimentar total; $\mathrm{VET}^{3}=$ valor energético total em $\mathrm{kcal} / 100 \mathrm{~g}$; $\mathrm{VET}^{4}=$ valor energético total em kJ/100g; $\mathrm{MP}=$ minimamente processado. Letras minúsculas diferentes na mesma linha significam diferença estatística $(\mathrm{p}<0,05$, Teste $t)$.

A tabela 2 apresenta a comparação dos compostos bioativos entre a cenoura in natura e minimamente processada, na base úmida. Os teores de vitamina $\mathrm{C}$, clorofila $\mathrm{B}$ e licopeno não apresentaram diferenças $(\mathrm{p}>0,05)$ entre a cenoura in natura e minimamente processada, ao passo que fenólicos totais, carotenoides totais, clorofila A e betacaroteno tiveram diferenças $(\mathrm{p}<0,05)$ entre os tratamentos. 
Tabela 2. Compostos bioativos (mg/100g) da cenoura (Daucus carota $\mathrm{L}$.) in natura e minimamente processada, na base úmida. Uberlândia-MG, 2013-2014.

\begin{tabular}{lcc}
\hline \multicolumn{1}{c}{ Compostos bioativos } & Cenoura in natura & Cenoura MP \\
\hline Fenólicos totais & $32,8 \pm 0,48^{\mathrm{b}}$ & $39,9 \pm 0,66^{\mathrm{a}}$ \\
Vitamina C & $21,3 \pm 0,50^{\mathrm{a}}$ & $18,3 \pm 2,28^{\mathrm{a}}$ \\
Carotenoides totais, dos quais: & $2,0 \pm 0,01^{\mathrm{a}}$ & $1,6 \pm 0,05^{\mathrm{b}}$ \\
$\quad$ Licopeno & $0,0 \pm 0,0^{\mathrm{a}}$ & $0,0 \pm 0,0^{\mathrm{a}}$ \\
$\quad$ & $2,0 \pm 0,01^{\mathrm{a}}$ & $1,6 \pm 0,05^{\mathrm{b}}$ \\
Betacaroteno & & $0,2 \pm 0,0^{\mathrm{b}}$ \\
$\quad$ Cutros pigmentos, dos quais: & $0,2 \pm 0,01^{\mathrm{a}}$ & $0,0 \pm 0,0^{\mathrm{a}}$ \\
\hline
\end{tabular}

Valores médios \pm desvio-padrão; $\mathrm{MP}=$ minimamente processado. Letras minúsculas diferentes na mesma linha significam que houve diferença estatística $(\mathrm{p}<0,05$, Teste $t)$.

A tabela 3 apresenta a comparação dos parâmetros físico-químicos em cenoura in natura e minimamente processada, na base úmida. Dentre os parâmetros físico-químicos, os sólidos solúveis não apresentaram diferença $(\mathrm{p}>0,05)$ entre a cenoura in natura e minimamente processada. Já a atividade antioxidante, a acidez titulável e o pH apresentaram redução dos teores $(\mathrm{p}<0,05)$, quando comparados à cenoura in natura.

Tabela 3: Parâmetros físico-químicos em cenoura (Daucus carota L.) in natura e minimamente processada, na base úmida. Uberlândia-MG, 2013-2014

\begin{tabular}{lcc}
\hline \multicolumn{1}{c}{ Parâmetros físico-químicos } & Cenoura in natura & Cenoura MP \\
\hline Atividade antioxidante $(\%)$ & $38,7 \pm 1,39^{\mathrm{a}}$ & $24,0 \pm 0,91^{\mathrm{b}}$ \\
Sólidos solúveis (öBrix) & $12,0 \pm 0,00^{\mathrm{a}}$ & $12,0 \pm 0,00^{\mathrm{a}}$ \\
Acidez titulável (\% ácido cítrico) & $1,4 \pm 0,02^{\mathrm{a}}$ & $1,9 \pm 0,04^{\mathrm{b}}$ \\
$\mathrm{pH}$ & $6,0 \pm 0,07^{\mathrm{a}}$ & $5,5 \pm 0,08^{\mathrm{b}}$ \\
\hline
\end{tabular}

Valores médios \pm desvio-padrão; $\mathrm{MP}=$ minimamente processado. Letras minúsculas diferentes na mesma linha significam que houve diferença estatística $(\mathrm{p}<0,05$, Teste $t)$. 
Apesar das inúmeras pesquisas na área de composição de alimentos, são escassas as pesquisas voltadas para a investigação do efeito do processamento mínimo em hortaliças, tendo o alimento in natura como "controle".

Primeiramente, os resultados do teor de umidade, proteínas, carboidratos "disponíveis" (por diferença), fibras alimentares, cinzas e do valor energético total (kcal e kJ) da presente pesquisa não demonstraram diferença significativa $(p>0,05)$ entre a cenoura in natura e a minimamente processada. Os resultados encontrados demonstraram que determinados componentes nutricionais (umidade, proteínas, carboidratos "disponíveis" por diferença, fibras alimentares e cinzas) da cenoura resistiram aos efeitos da injúria, decorrentes do processamento mínimo.

Além disso, a divergência encontrada entre os resultados dos carboidratos "disponíveis" da cenoura, obtidos por diferença e pelo método fenol sulfúrico, tanto in natura quanto minimamente processada, pode ser explicada pelos erros analíticos que se somaram a cada mensuração dos componentes da composição centesimal (umidade, proteínas, lipídios, cinzas e fibras alimentares). ${ }^{13}$ $\mathrm{O}$ valor energético total (em kcal e kJ) não apresentou diferença significativa $(\mathrm{p}>0,05)$ entre a cenoura in natura e a minimamente processada.

A presente pesquisa demonstrou que o teor de fenólicos totais encontrados na cenoura minimamente processada foi superior ao encontrado na cenoura in natura $(\mathrm{p}<0,05)$. Em pesquisa realizada com vegetais minimamente processados, ${ }^{25}$ verificou-se que a cenoura minimamente processada teve diminuição do teor de fenólicos totais quando comparada à in natura. De uma maneira geral, esperava-se diminuição dos fenólicos totais após o processamento mínimo, devido à injúria tecidual do vegetal..$^{25}$ Entretanto, também foi discutido que determinados vegetais podem sofrer aumento do teor de fenólicos após o processamento mínimo, quando comparados ao alimento in natura, decorrente, provavelmente, do tipo de corte e manuseio (manual ou com o auxílio de equipamentos). Sugere-se que o manuseio do alimento durante o processamento mínimo com o auxílio de equipamentos adequados (lâmina afiada) leva a menor perda de fenólicos, quando comparado ao manuseio com utensílios domésticos como, por exemplo, facas e ralador manual. ${ }^{25,26}$

Em relação à vitamina $\mathrm{C}$, o teor encontrado na cenoura minimamente processada foi igual ao encontrado na cenoura in natura ( $\mathrm{p}>0,05)$, embora houvesse tendência de diminuição no teor de vitamina C da cenoura minimamente processada $(18,3 \mathrm{mg} / 100 \mathrm{~g})$ quando comparada à in natura (21,30 mg/100g). Alves et al..$^{27}$ encontraram $10 \mathrm{mg} / 100 \mathrm{~g}$ de vitamina C em cenoura minimamente processada, valor numericamente inferior ao encontrado no presente trabalho $(18,3 \mathrm{mg} / 100 \mathrm{~g})$. Tal variação no teor de vitamina $\mathrm{C}$ pode ocorrer devido à diferença de cultivar, época de colheita, solo e clima. ${ }^{13}$

Dentre os carotenoides analisados na cenoura, tanto na in natura quanto na minimamente processada, o betacaroteno destacou-se por estar presente em maior quantidade. O betacaroteno 
possui atividade pró-vitamina A, atua na prevenção de doenças crônicas não transmissíveis e é responsável pela coloração amarelo-alaranjada da cenoura. ${ }^{28}$

Com relação aos outros carotenoides e pigmentos, não foram encontradas quantidades expressivas de clorofila A, e o licopeno e a clorofila B não foram identificados. Em relação aos tratamentos, a cenoura in natura apresentou maiores quantidades $(\mathrm{p}<0,05)$ de carotenoides totais e de betacaroteno quando comparada à minimamente processada. $\mathrm{O}$ valor de betacaroteno encontrado em cenoura minimamente processada $(1 \mathrm{mg} / 100 \mathrm{~g})$ de outro estudo aproximou-se, numericamente, da quantidade aqui encontrada $(1,6 \mathrm{mg} / 100 \mathrm{~g}){ }^{27}$

Dentre os parâmetros físico-químicos (atividade antioxidante, sólidos solúveis, acidez titulável e $\mathrm{pH})$, apenas os sólidos solúveis não apresentaram diferença $(\mathrm{p}>0,05)$ entre a cenoura in natura e a minimamente processada, demonstrando que, de uma maneira geral, esses parâmetros são sensíveis às etapas do processamento mínimo. Os sólidos solúveis encontrados para as duas amostras (12,0 ํㅏix) aproximaram-se, numericamente, dos valores encontrados em abóbora minimamente processada $\left(12,2\right.$ 을 ${ }^{29}$

$\mathrm{O}$ pH da cenoura minimamente processada apresentou redução $(\mathrm{p}<0,05)$ quando comparada à cenoura in natura. $\mathrm{O} \mathrm{pH}$ da cenoura minimamente processada (cerca de 6,0$)$ de outro estudo ${ }^{27}$ aproximou-se, numericamente, do $\mathrm{pH}$ encontrado $(5,5)$. Consequentemente, a acidez titulável da cenoura minimamente processada do presente estudo aumentou $(\mathrm{p}<0,05)$ em relação à cenoura in natura. Já em estudo conduzido por Ayub, Spinardi e Gioppo, ${ }^{30}$ a acidez titulável (expresso em ácido málico) em amostras de rabanete (considerado uma raiz) minimamente processadas foi inferior ao in natura.

As condições após a colheita de vegetais e o processamento (pode-se exemplificar o processamento mínimo) comumente diminuem de maneira significativa os teores de vitamina C e de carotenoides, influenciando a atividade antioxidante do vegetal. ${ }^{31}$ No presente estudo, a atividade antioxidante da cenoura minimamente processada $(24,0 \%)$ apresentou redução $(\mathrm{p}<0,05)$ quando comparada à cenoura in natura $(38,7 \%)$ e este resultado era esperado devido ao declínio dos carotenoides e da vitamina C (embora não significativo) que apresentam alta capacidade antioxidante. ${ }^{32}$

Vale ressaltar que, até o presente momento, não foram encontrados estudos que comparassem as possíveis alterações na composição centesimal, teor de vitamina $\mathrm{C}$, carotenoides, sólidos solúveis, acidez titulável (\% ácido cítrico), pH e atividade antioxidante em cenoura in natura e minimamente processada.

Dentre os 18 parâmetros de qualidade nutricional e físico-química analisados (umidade, proteínas, lipídios, carboidratos "disponíveis", fibras alimentares, cinzas, energia, fenólicos totais, vitamina C, carotenoides totais, licopeno, betacaroteno, clorofila A, clorofila B, atividade antioxidante, sólidos solúveis, acidez titulável e pH), oito parâmetros (cerca de 44\% do total) 
apresentaram modificações em relação à cenoura in natura, ou seja, houve alteração significativa $(\mathrm{p}<0,05)$ em considerável parte dos parâmetros avaliados na cenoura minimamente processada. A cenoura minimamente processada apresentou valores menores $(\mathrm{p}<0,05)$ em seis parâmetros analisados (lipídios, carotenoides totais, betacaroteno, clorofila $\mathrm{A}$, atividade antioxidante e $\mathrm{pH}$ ) quando comparada à cenoura in natura e apresentou valores maiores $(\mathrm{p}<0,05)$ em dois parâmetros analisados (acidez titulável e fenólicos).

Então, considerando os resultados do presente estudo, a cenoura in natura apresentou melhor valor nutricional quando comparada com a cenoura minimamente processada. A perda de parte da qualidade nutricional e físico-química da cenoura após o processamento mínimo pode ser explicada pelas modificações e/ou rompimento da estrutura do tecido vegetal durante as etapas de pré-preparo, levando a cenoura à injúria tecidual. A injúria no vegetal é consequência da retirada da casca e do corte feito nas amostras de cenoura, resultando em aumento da respiração (ou taxa respiratória), da atividade microbiológica e da evaporação de água., ${ }^{1,25,33}$

Como limitação do presente estudo, foi realizada somente uma única tomada de ensaio em uma amostra de cenoura, sugerindo que os dados são apenas indicativos e que mais estudos precisam ser conduzidos para verificar as possíveis modificações nutricionais e físico-químicas em vegetais, particularmente a cenoura, após o processamento mínimo.

Novos estudos na área de processamento mínimo de vegetais são importantes para certificar sua qualidade, sobretudo no que diz respeito aos parâmetros nutricionais e físico-químicos, e servir de subsídio para que os profissionais de saúde possam orientar adequadamente a população, pois tais produtos são bastante comuns no mercado alimentício moderno.

\section{Conclusões}

Ao analisar os dois tratamentos de cenoura, pode-se concluir que a cenoura in natura possui maior qualidade nutricional e físico-química quando comparada com a cenoura minimamente processada, pois valores de lipídios, carotenoides totais, betacaroteno, clorofila A, atividade antioxidante e pH sofreram redução após o processamento mínimo da cenoura.

As hortaliças, particularmente a cenoura, possuem níveis expressivos de compostos bioativos, sobretudo compostos fenólicos e carotenoides, e alta atividade antioxidante. Dessa forma, seria vantajoso o consumo de cenoura in natura, visto que após o processamento mínimo, os teores de alguns nutrientes e a potencialidade antioxidativa tendem a diminuir. Porém, considerando as necessidades atuais dos consumidores de alimentos convenientes, inovadores e saudáveis, a cenoura minimamente processada se adequa a esses anseios, mesmo que apresente teores decrescidos de alguns nutrientes. 
E, embora haja perdas naturais de qualidade, provenientes das modificações fisiológicas após a colheita da cenoura, sugere-se que seu processamento mínimo seja otimizado, constantentemente monitorado e com a utilização de equipamentos calibrados, padronizados e de alta tecnologia, a fim de evitar perdas nutricionais e físico-químicas deste vegetal.

Para finalizar, são de grande importância mais estudos que analisem a qualidade nutricional e os parâmetros físico-químicos em cenoura minimamente processada, com o objetivo de investigar o efeito do seu processamento mínimo.

\section{Referências}

1. Junqueira AH, Luengo RFA. Mercados diferenciados de hortaliças. Horticultura Brasileira 2000; 18(2):95-9.

2. Vilela NJ, Macedo MMC. Fluxo de poder no agronegócio: o caso das hortaliças. Horticultura Brasileira 2000; 18(2):88-94.

3. Regmi A, Gehlhar M. New directions in global food markets. USDA, Agriculture Information Bulletin 2005; 794:1-3.

4. Serviço Brasileiro de Apoio às Micro e Pequenas Empresas. Hortaliças minimamente processadas. Relatório completo. Estudo de Mercado - SEBRAE 2008. 170 p.

5. Damasceno KSFSC, Alves MA, Mendonça SC, Guerra NB, Stamford, TL. Melão minimamente processado: um controle de qualidade. Ciência e Tecnologia de Alimentos 2005; 25(4):651-8.

6. Moretti CL. Manual de processamento mínimo de frutas e hortaliças. Brasília: Embrapa Hortaliças; 2007.

7. Horst MA. Compostos bioativos de alimentos. In: Cozzolino SMF, Cominetti C. Bases bioquímicas e fisiológicas da nutrição: nas diferentes fases da vida, na saúde e na doença. Barueri: Manole; 2013. p. 593-615.

8. Bastos DHM, Rogero MM, Arêas JAG. Mecanismos de ação de compostos bioativos dos alimentos no contexto de processos inflamatórios relacionados à obesidade. Arquivos Brasileiros de Endocrinologia e Metabologia 2009; 53:53-5.

9. Spagnol WA, Park KJ, Sigrist JMM. Taxa de respiração de cenouras minimamente processadas e armazenadas em diferentes temperaturas. Ciência e Tecnologia de Alimentos 2006; 26(3):550-4.

10. Brecht JK. Physiology of lightly processed fruits and vegetables. Horticultural Science 1995; 30(1):18-22.

11. Lima KSC, Lima ALS, Luchese RH, Godoy RLO, Sabaa-Srur AUO. Cenouras minimamente processadas em embalagens com atmosferas modificadas e tratadas com radiação gama: avaliação microbiológica, físico-química e química. Ciência e Tecnologia de Alimentos 2003; 23(2):240-250.

12. UNICAMP. Núcleo de Estudos e Pesquisas em Alimentação. Tabela Brasileira de Composição de Alimentos. Campinas: NEPA; 2001. 32 p. 
13. Da-Paz JG, Pacheco P, Da-Silva CO, Pascoal GB. Análise da composição nutricional e de parâmetros físico-químicos do pequi (Caryocar brasiliense camb) in natura. Revista Científica Linkania Master 2014; 1:73-86.

14. Oliveira LE, Silva CO, Pascoal GB. Comparação entre a composição nutricional dos rótulos e as análises laboratoriais de queijos minas frescal (tradicional e light). Revista do Instituto de Laticínios Cândido Tostes 2014; 69:280-8.

15. Pacheco P, Da-Paz JG, Silva CO, Pascoal GB. Composição centesimal, compostos bioativos e parâmetros físico-químicos do Jenipapo (Genipa americana L.) in natura. DEMETRA: Alimentação, Nutrição \& Saúde 2014; 9:1041-1054.

16. Cecchi HM. Fundamentos teóricos e práticos em análise de alimentos. $2^{\mathrm{a}}$ ed. Campinas, SP: UNICAMP; 2003.

17. Instituto Adolfo Lutz. Normas analíticas do Instituto Adolfo Lutz. Métodos físico-químicos para análise de alimentos. São Paulo: Instituto Adolfo Lutz; 2008.

18. Association of Official Analytical Chemists. Official methods of analysis of the AOAC International. $19^{\text {th }}$ ed. Washington: AOAC; 2012.

19. Brasil. RDC n 360, de 23 de dezembro de 2003. Regulamento técnico sobre rotulagem nutricional de alimentos embalados. Diário Oficial da União 26 dez. 2003.

20. Dubois MKA, Gilles JK, Hamilton PA, Smith R, Smith F. Colorimetric method for determination of sugars and related substances. Analytical Chemistry 1956; 28(3):350-6.

21. Singleton VL, Rossi JR. Colorimetry of total phenolics with phosphomolybdic phosphotungstic acid reagents. American Journal of Enology and Viticulture 1965; 16:144-158.

22. Masaijasu N, Ichiji Y. Simple method for simultaneous determination of chlorophyll and carotenoids in tomato fruit. Journal of the Japanese Society for Food Science and Technology 1992; 10(39):925-8.

23. Brand-Wiliams W, Cuvelier ME, Berset C. Use of a free radical method to evaluate antioxidant activity. Food Science and Technology 1995; 28:25-30.

24. Universidade de São Paulo. Faculdade de Ciências Farmacêuticas. Departamento de Alimentos e Nutrição Experimental. Tabela brasileira de composição de alimentos da USP. versão 5.0. [Internet]. [acesso em: 02 set. 2014]. Disponível em: http://www.fcf.usp.br/tabela

25. Alarcón-Flores MI, Romero-González R, Martínez VJL, Egea GFJ, Garrido FA. Monitoring of phytochemicals in fresh and fresh-cut vegetables: a comparison. Food Chemistry 2014; 142:392-7.

26. Mishra BB, Gautam S, Sharma A. Browning of fresh-cut eggplant: impact of cutting and storage. Postharvest Biologyand and Technology 2012; 67:44-51.

27. Alves JA, Vilas Boas EVB, Souza EC, Vilas Boas BM, Piccoli RH. Vida útil de produto minimamente processado composto por abóbora, cenoura, chuchu e mandioquinha-salsa. Ciência e Tecnologia de Alimentos 2010; 30(3):625-33. 
28. Carvalho PGB, Machado CMM, Moretti CL, Fonseca MEN. Hortaliças como alimentos funcionais. Horticultura Brasileira 2006; 24(4):397-404.

29. Silva AVC, Oliveira DSN, Yaguiu P, Carnelossi MAG, Muniz EN, Narain N. Temperatura e embalagem para abóbora minimamente processada. Ciência e Tecnologia de Alimentos 2009; 29(2):391-4.

30. Ayub RA, Spinardi B, Gioppo M. Storage and fresh cut radish. Acta Scientiarum 2013; 35(2):241-4.

31. Jones RB, Stefanelli D, Tomkins RB. Pre-harvest and post-harvest factors affecting ascorbic acid and carotenoid content in fruits and vegetables. Acta Horticulturae 2015; 1106:31-42.

32. Silva MLC, Costa RS, Santana AS, Koblitz MGB. Compostos fenólicos, carotenoides e atividade antioxidante em produtos vegetais. Semina: Ciências Agrárias 2010; 31(3):669-82.

33. Ferreira TA, Silva CO, Pascoal GB. Análise físico-química em repolho branco (Brassica oleracea) minimamente processado durante o acondicionamento sob refrigeração. Revista Científica Linkania 2014; 1(4):59-72. 
